\title{
Pseudoaneurysm of the ascending aorta: case report of a donor-derived Pseudomonas infection in a heart transplant recipient
}

\author{
Szilvia Kugler ${ }^{1 *}$, Miklós Pólos ${ }^{1}$, Ákos Király , Ákos Pataki ${ }^{1}$, Ádám Koppányi ${ }^{1}$, Tamás Varga $^{2}$, Zsófia Szakál-Tóth ${ }^{1}$, \\ Nóra Parázs ${ }^{1}$, Tímea Teszák ${ }^{1}$, Zoltán Tarjányi ${ }^{1}$, Gyula Prinz ${ }^{1}$, István Hartyánszky¹, Zoltán Szabolcs ${ }^{1}$, \\ Béla Merkely ${ }^{1}$ and Balázs Sax ${ }^{1}$
}

\begin{abstract}
Background: Mycotic aortic pseudoaneurysm is a rare complication after heart transplantation (HTX) with remarkable mortality. Intrathoracic infection is a well-documented predisposing factor for this disease. Staphylococcus aureus, Pseudomonas aeruginosa or Candida species are commonly isolated from resected specimens of the pseudoaneurysms. We demonstrate a unique case of mycotic pseudoaneurysm caused by presumably donor-derived Pseudomonas infection in a heart transplant recipient.
\end{abstract}

Case presentation: Our 67-year-old male patient treated with diabetes mellitus underwent HTX. The donor suffered from epiglottic abscess and pneumonia with known microorganisms including Pseudomonas, therefore both the donor and recipient received targeted antimicrobial therapy and prophylaxis. Five months after the uneventful HTX, lab test of the asymptomatic patient showed moderate, increasing C-reactive protein level without obviuos source of infection. Chest computed tomography showed a large $(90 \mathrm{~mm})$ saccular dilatation of the tubular portion of ascending aorta. Urgent surgical intervention identified a pseudoaneurysm, histological examinations and cultures of the resected aorta verified Pseudomonas aeruginosa aortitis, while all blood cultures remained negative. Retrospective interrogation of other transplanted organs of the donor supported donor-derived infection as the transport fluid of the right kidney grew Pseudomonas. The patient received 3 weeks of ceftazidime followed by 7 months of oral ciprofloxacin therapy. One year after the operation the patient was asymptomatic with normal inflammatory markers.

Conclusions: Donor-derived infection is a rare but potential cause of aortitis. Early diagnosis, surgical intervention and adjuvant antibiotic therapy seem to be the keys to successful management of mycotic pseudoaneurysms after HTX.

Keywords: Aortic pseudoaneurysm, Pseudomonas aeruginosa, Heart transplantation, Donor-derived infection, Case report

*Correspondence: kuglerszilvia92@gmail.com

1 Heart and Vascular Center, Semmelweis University, 68 Városmajor Street,

1122 Budapest, Hungary

Full list of author information is available at the end of the article

\section{Background}

After open heart surgeries, pseudoaneurysms of the thoracic aorta may develop from cannulation sites, suture lines or anastomotic sites [1]. Microorganisms tend to localize at the sites of previous injury in the wall of the vessel which predisposes to the formation of infected (or so called mycotic) pseudoaneurysms 
[2]. After heart transplantation (HTX), immunosuppression renders patients vulnerable to infection, which may lead to increased risk for aortic suture line insufficiency and the formation of mycotic pseudoaneurysms compared to immunocompetent individuals. Resected specimen of the mycotic ascending aortic pseudoaneurysms of heart transplantat patients frequently grows Staphylococcus aureus, Pseudomonas (P.) aeruginosa or Candida species. Based on literature data discussed in details below, two-thirds of patients recover after treatment. Despite the potentially fatal outcome of these complications, there are some controversial issues regarding the optimal surgical and antibiotic treatment.

We describe the case of an almost asymptomatic patient in whom a $P$. aeruginosa pseudoaneurysm of the ascending aorta developed five months after HTX at the aortic suture line. In this case no obvious concomitant infection was found at the patient and donor-derived infection is suspected. To the best of our knowledge, this is the first case, in which a mycotic aortic pseudoaneurysm was formed due to a probably donor-derived $P$. aeruginosa infection. We demonstrate the diagnostic process, discuss the antibiotic management and surgical treatment and also review the relevant literature.

\section{Case presentation}

\section{Patient information}

A 67-year-old man who had undergone orthotopic HTX 5 months before was admitted to our clinic for a surveillance endomyocardial biopsy (EMB) in perfect physical condition and asymptomatic. There was no history of fever episodes, other symptoms of infection, dyspnea, chest pain or malaise.

His medical history is significant for hypertension and chronic renal failure, the etiology of end stage heart failure was dilated cardiomyopathy with non-significant coronary stenosis. Brain death of the 31-year-old donor developed after a successful reanimation from a respiratory and cardiac arrest which was caused by an epiglottic abscess. The donor was septic with fever and high procalcitonin level (maximum $16 \mathrm{ng} / \mathrm{ml}$ ). Cultures of the abscess grew Klebsiella aerogenes, Enterococcus faecalis, Staphylococcus aureus, Hafnia alvei, Finegoldia magna, Prevotella bivia and Prevotella oris. Chest x-ray and ultrasound showed right sided basal pneumonia. Microbiological examination of bronchoalveolar lavage fluid revealed the presence of Candida kefyr and multisensitive $P$. aeruginosa (results were validated on the day after transplantation). Donor received initial ceftriaxone therapy for 6 days (2000 mg once daily) that was changed to imipenem/cilastatin (500 $\mathrm{mg}$ four times daily), given for the last $24 \mathrm{~h}$ before donation.

Immunosuppression of the patient consisted induction therapy (3-day course of antithymocyte globulin and high-dose methylprednisolon) and triple maintenance immunosuppressive regimen including methylprednisolone ( $8 \mathrm{mg}$ once daily), tacrolimus (aiming a trough level of $10-15 \mathrm{ng} / \mathrm{ml}$ in the first 3 months, then $8-10 \mathrm{ng} /$ $\mathrm{ml}$ ) and mycophenolic acid (720 mg twice daily). Perioperative prophylaxis considering the microbiology culture results of donor consisted of meropenem (1000 mg three times daily) and vancomycin (1000 mg twice daily), given for $48 \mathrm{~h}$. The postoperative course was uncomplicated. Transthoracic echocardiographies (TTE) revealed good graft function with normal estimated pulmonary artery systolic pressure. No rejection episodes could be found with surveillance endomyocardial biopsies.

Retrospectively, outcomes of other transplanted organs were interrogated from Eurotransplant. Liver, both kidneys, vascular homografts and connective tissue were explanted from the same donor. Transport fluid of the right kidney grew Pseudomonas, therefore the recipient of this organ received piperacillin/tazobactam prophylaxis. Preservation fluids of other organs were not cultured. Neither the recipient of the left kidney, nor liver recipient received any anti-Pseudomonas prophylaxis. No donor-derived infection was reported after transplantation of left and right kidneys, liver and connective tissue. Vascular homografts were discarded for safety reasons.

\section{Clinical findings}

At the beginning of June, the patient was scheduled for a regular EMB procedure. He presented with no symptoms except of a gradual weight loss of $15 \mathrm{~kg}$ (19\% of his initial body weight) during 4 months. Physical examination was unrevealing. His blood pressure had been in target range for several weeks. No fever or subfebrility was detected.

\section{Diagnostic assessment}

Routine lab tests showed normal white blood cell count $(8,9 \mathrm{G} / \mathrm{l})$ with $87 \%$ neutrophyl granulocytes and a remarkable $\mathrm{C}$-reactive protein (CRP) elevation showing an increasing tendency in the previous two months (7-24-31-57 mg/l). In addition, normocyter anemia (hemoglobin $104 \mathrm{~g} / \mathrm{l}$, hematocrit 33\%) and impaired kidney function (glomerular filtration rate $39 \mathrm{ml} / \mathrm{min}$, creatinin $155 \mu \mathrm{mol} / \mathrm{l}$ ) was detected. Urinanalysis excluded pyuria or bacteruria. SARS-CoV-2 polymerase chain reaction test was negative.

TTE showed good graft function without any relevant abnormalities. Histological analysis of the EMB showed 
no rejection. Nor chest x-ray, neither abdominal sonography showed any relevant abnormalities. To identify the source of inflammation, a chest and abdominal computed tomographic (CT) scan was performed. This revealed a large, irregular, saccular dilatation of the tubular portion of ascending aorta with a maximum diameter of $90 \mathrm{~mm}$ (Fig. 1a, b).

\section{Therapeutic intervention}

Based on chest CT findings, an urgent surgical intervention was performed on the following day. Before performing median resternotomy, the left femoral artery was canulated through an $8 \mathrm{~mm}$ dacron vascular prosthesis for arterial line of cardiopulmonary bypass (CPB), to ensure the safety of patient in case of a pseudoaneurysm rupture. Myocardium protection was provided by antegrade Custodiol cardioplegia. After aortic crossclamp, the aortic pseudoaneurysm (Fig. 2a) was opened. We identified the rupture of the former aortic polipropilene running suture (Fig. 2b), which could be the basis for the pseudoaneurysm formation between the donor and the recipient aorta. The tissue quality of both donor and recipient aorta seemed to be normal macroscopically. However, the tissues where the pseudoaneurysm wall attached to the donor aortic wall contained purulent-like debris, this was sent for microbiology examination. We resected the pseudoaneurym thoroughly and performed an aorto-aortic interposition between the recipient's distal ascendent aorta and donor's sinotubular junction with a $28 \mathrm{~mm}$ dacron vascular prosthesis (Fig. 2c). CPB time was $78 \mathrm{~min}$, aortic cross clamp time was $48 \mathrm{~min}$.

The patient recovered from surgery uneventfully. TTE showed unchanged graft function. No decline in renal function was detected.

Histologic evaluation of the resected pseudoaneurysm and aortic walls of the recipient and donor showed
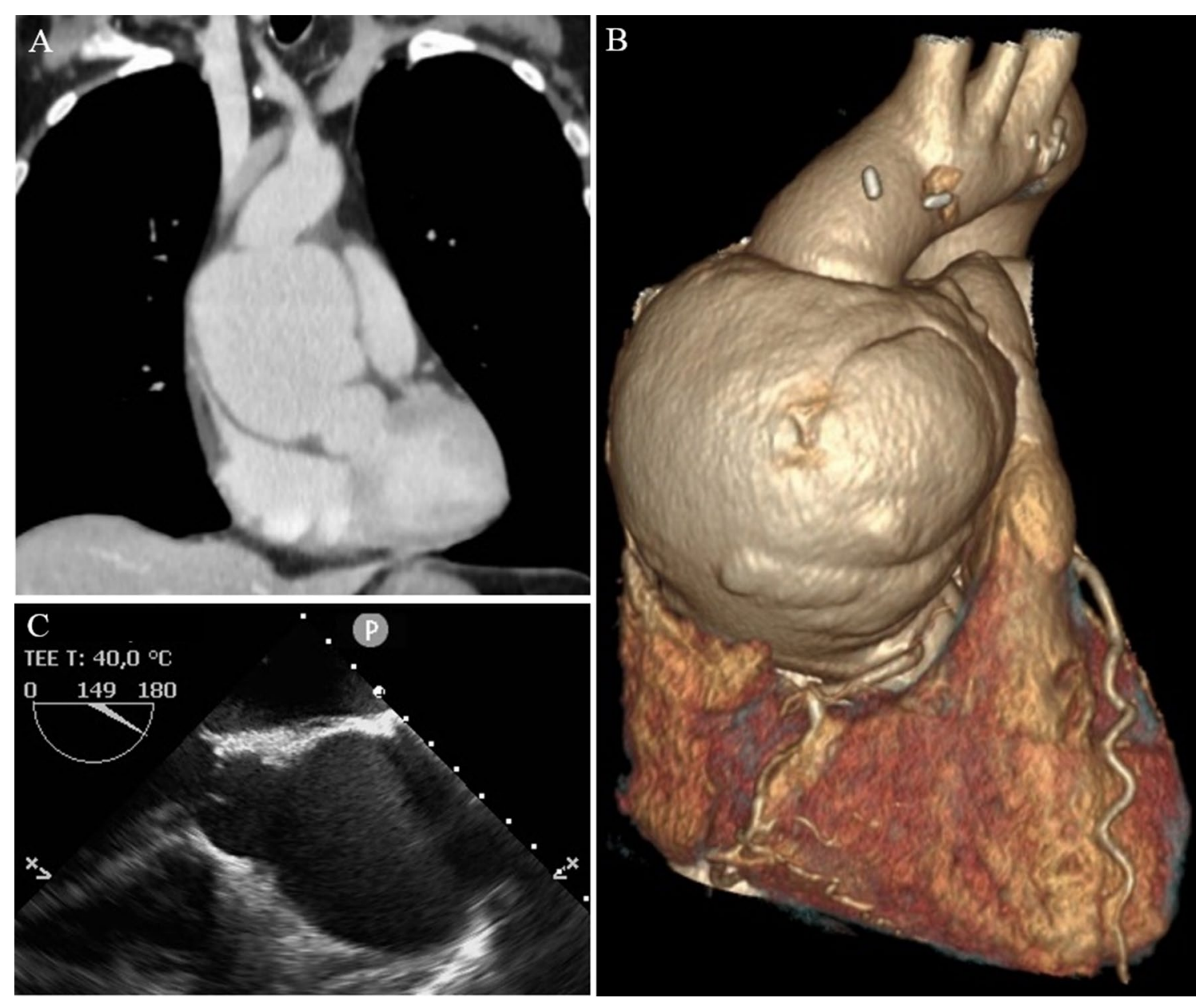

Fig. 1 Perioperative imaging of the ascending aortic pseudoaneurysm. Coronal plane of CT scan (A) and three-dimensional CT reconstruction (B) showed a huge, saccular dilatation of the tubular portion of ascending aorta. This abnormality could be also visualised by intraoperative transesophageal echocardiography $(\mathbf{C})$ 


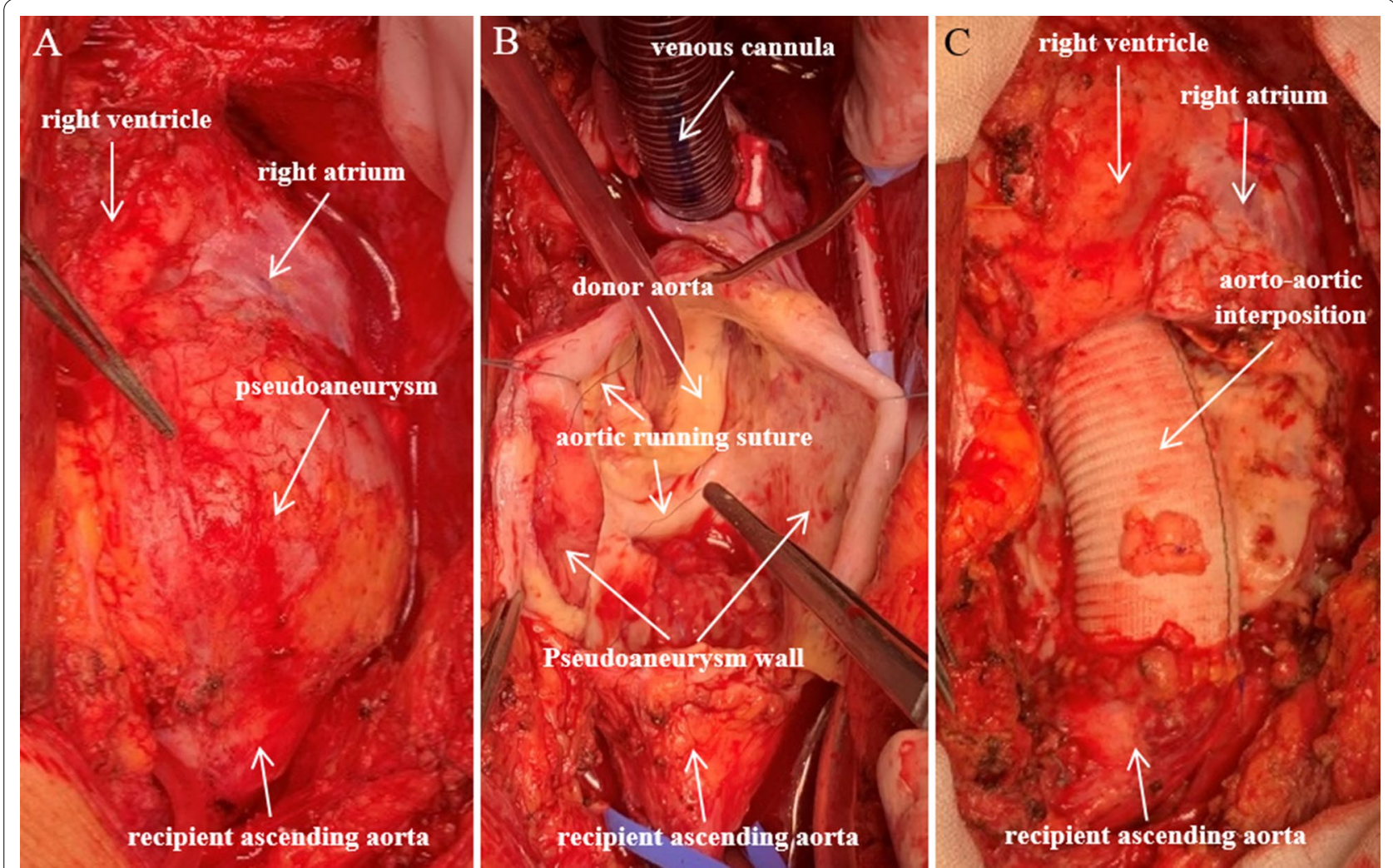

Fig. 2 Intraoperative photographs of the ascending aorta. Images of the ascending aorta before and after its reconstruction. The aortic pseudoaneurysm was found to be intact after sternotomy (A). After opening it, rupture of the former running suture between the donor and the recipient aorta was detected (B). The pseudoaneurysm was resected and an aorto-aortic interposition was performed (C)

infectious aortitis, but no pathogenes could be identified. However, cultures of the resected specimens grew multisensitive P. aeruginosa. Serial blood cultures and urine culture were repeatedly negative.

The patient received 18 days of intravenous treatment of ceftazidime ( $2000 \mathrm{mg}$ three times daily) followed by 7 months of oral ciprofloxacin (500 mg twice daily) from the day of discharge. The targeted antibiotic therapy resulted in significant decrease in CRP level.

In the early postoperative period mycophenolic acid therapy was transiently stopped and reinitiated in a reduced dose when inflammatory markers decreased. Tacrolimus and steroid regimen was maintained.

\section{Follow-up and outcome}

At follow-up examinations the patient was doing well without fever, TTE-s showed no abnormalities and CRP level remained normal. Blood pressure could be kept in target range. EMB-s showed no sign of rejection.

19 days and 7.5 months after the surgery chest CT angiograms showed intact interposition graft of the ascending aorta with no sign of recurrent aortic pseudoaneurysm (Fig. 3). Based on this finding and the continuously normal inflammatory markers of the patient, we decided to discontinue the oral ciprofloxacin therapy almost 8 months after the operation.

At his latest follow-up one year after the operation the patient is still asymptomatic with normal inflammatory markers.

\section{Discussion and conclusions}

Mycotic pseudoaneurysms of the ascending aorta are rare complications after cardiac surgery and are caused by growth of microorganisms in the vessel wall. The name mycotic aneurysm was coined by Osler to describe aneurysms associated with bacterial endocarditis [3]. These were noted to have the appearance of "fresh fungus vegetations", however, the majority of mycotic aneurysms are caused by bacteria. Immunosuppression is a major predisposing factor for this complication.

After thorough review of literature we identified 49 case reports of mycotic pseudoaneurysms of the ascending aorta after HTX. Median time between transplantation and diagnosis of pseudoaneurysm was 6 months (Fig. 4). Resected specimen of ascending aortic pseudoaneurysms of heart transplant patients frequently grows 


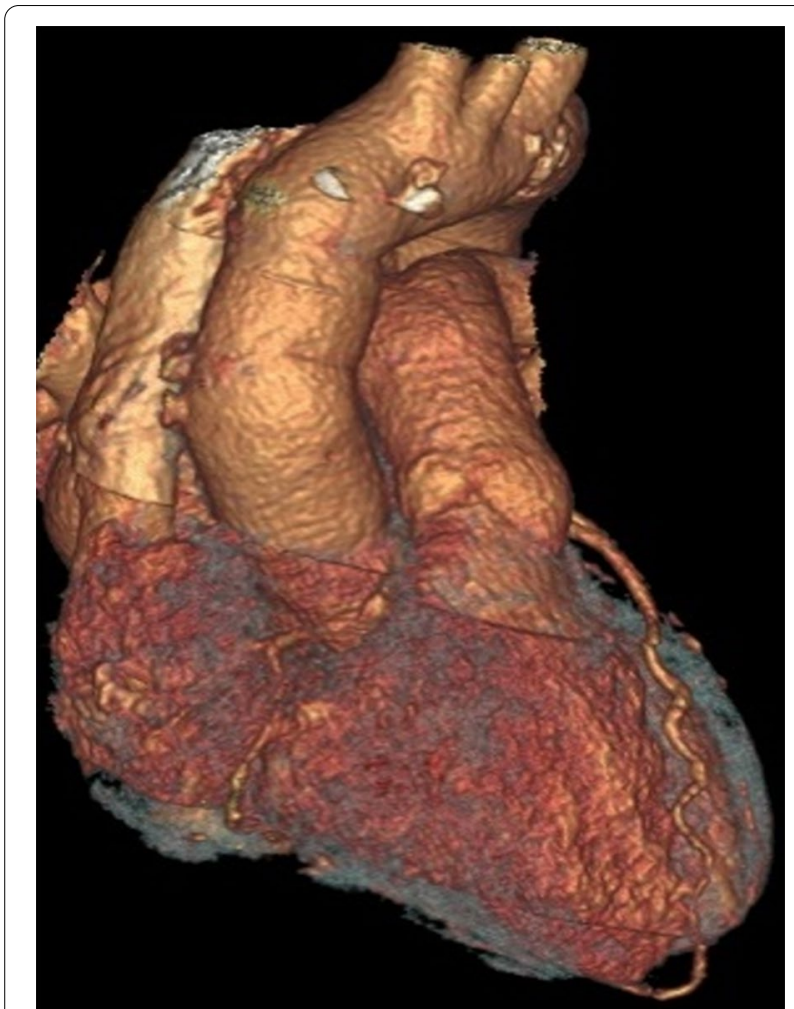

Fig. 3 Three-dimensional CT image of the postoperative state of the ascending aorta. Three-dimensional CT reconstruction shows an intact interposition graft of the ascending aorta 7.5 months after the surgery

Staphylococcus aureus [4-17], P. aeruginosa [7, 14, 1823] or Candida species, [7, 14, 21, 24-29] but other grampositive $[7,14,30,31]$ or gram-negative $[14,32]$ bacteria and Aspergillus fumigatus [33-35] are also reported as potential pathogens.

The following predisposing factors for aortic wall infection and formation of mycotic pseudoaneurysm are documented in literature: intrathoracic infection (50\%) [6-8, $10,14-16,24,25,30,33,35,36]$, pneumonia or bronchitis (20\%) $[4,13,17,19,21,25,26]$, heart-lung transplantation $(17.5 \%)[4,14,15,19,25]$, reoperation due to bleeding (15\%), [4, 8, 13, 31] diabetes mellitus (15\%), [7, 12, 15, $31,35,37]$ infection of a previous ventricular assist device $(12.5 \%)$ [9, 14, 22, 23], transmission of microorganisms from the donor $(7.5 \%)[8,25]$, acute cholecystitis (5\%) $[28,33]$, urinary tract infection $(5 \%)[18,31]$, other septicaemia (5\%), [17, 21] pacemaker endocarditis (2.5\%), [13] skin disruption (2.5\%), [29] heart-lung retransplantation (2.5\%) [25].

In our patient there was no evidence of any obvious concomitant infection. However epiglottic abscess and Pseudomonas pneumonia of the donor is notable. Although both the donor and recipient received broadspectrum antibiotic treatment, donor-derived Pseudomonas infection is possible as transport fluid of the donated right kidney also grew $P$. aeruginosa. $P$. aeruginosa grown from donor and recipient samples equally showed sensitivity for all antibiotics tested, which means they possessed a similar phenotype. Furthermore, the donor received only $24 \mathrm{~h}$ of adequate antibiotic therapy against Pseudomonas (imipenem/cilastatin) before the donation which might not have been long enough. These observations support the theory of donor-derived infection further. All available cases of Pseudomonas mycotic pseudoaneurysm in heart transplant recipients is summarized in Table 1. It is noteworthy that donor-derived

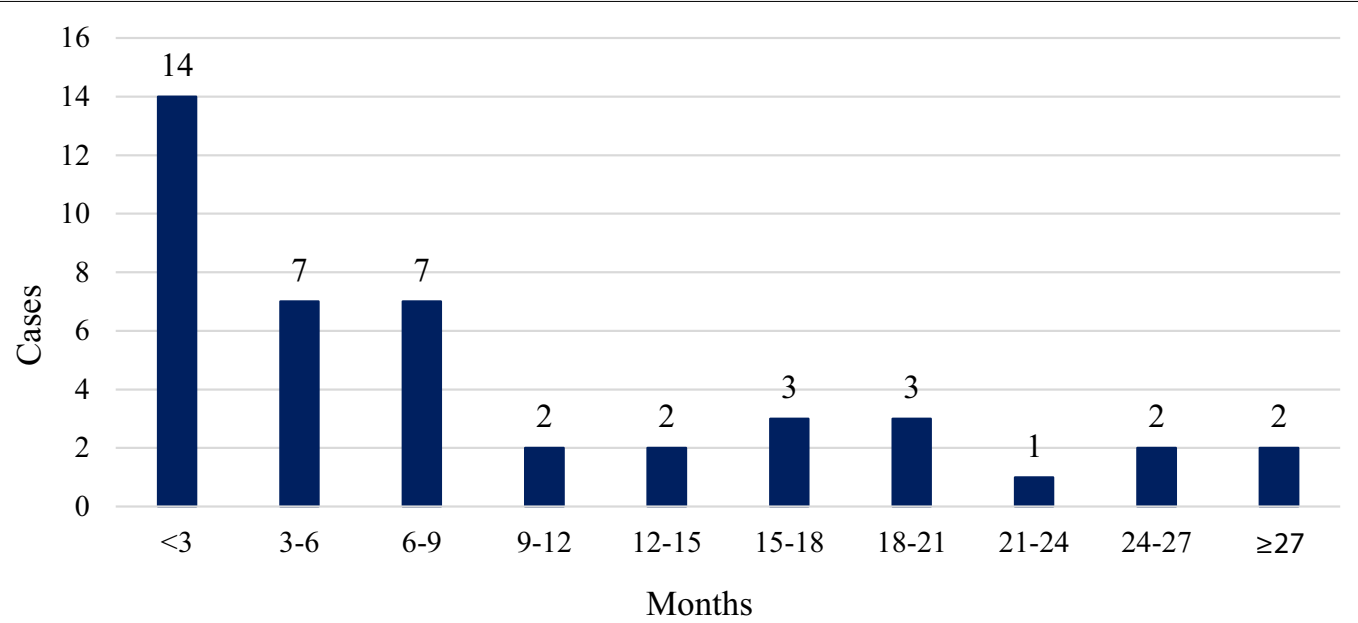

Fig. 4 Time between heart transplantation and detection of pseudoaneurysm. Based on literature data, majority of the ascending aortic mycotic pseudoaneurysms are detected less than three months after heart transplantation. After nine months, number of newly diagnosed cases decreases markedly (49 cases reviewed, missing data in 6 cases) 


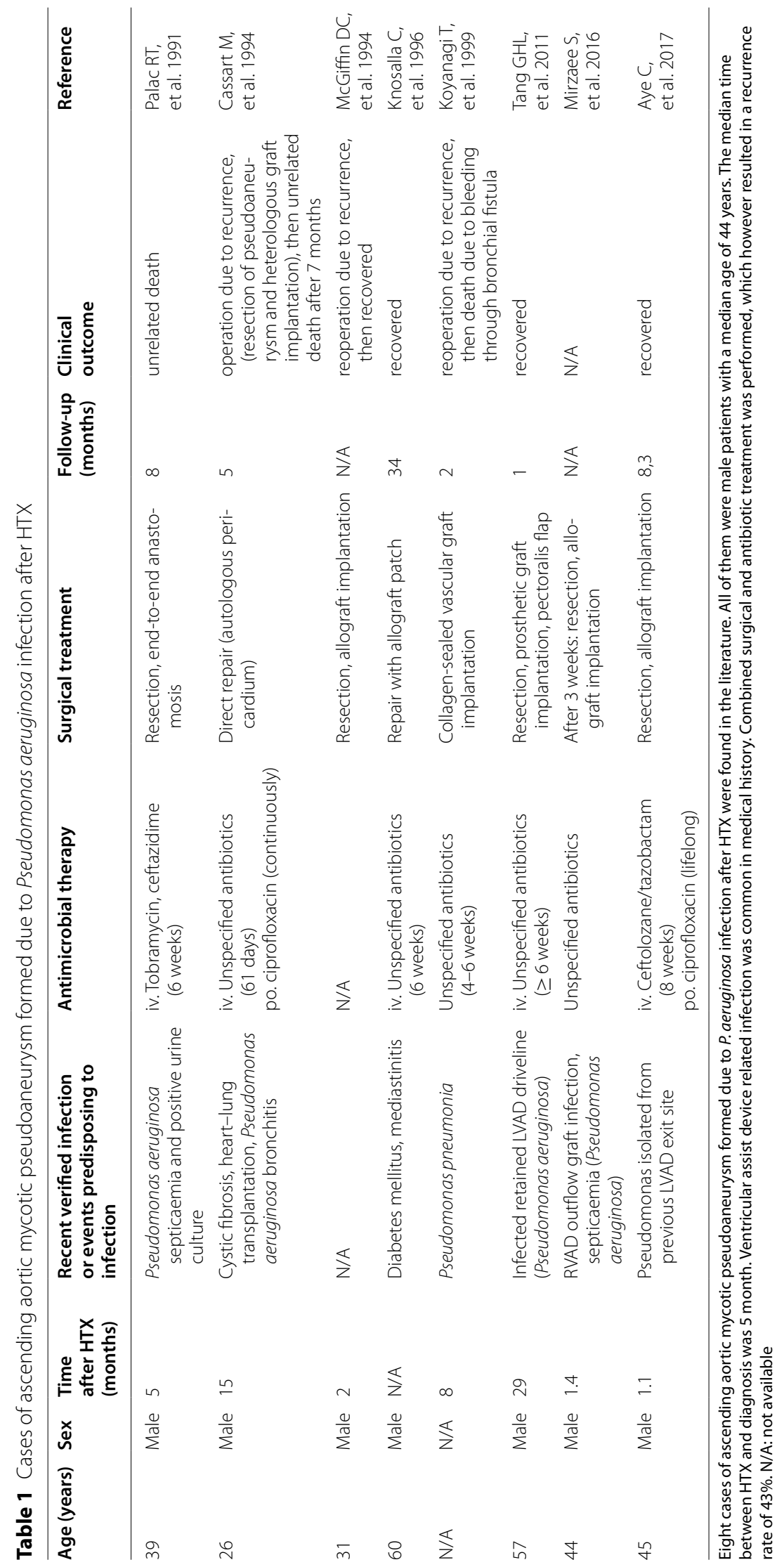




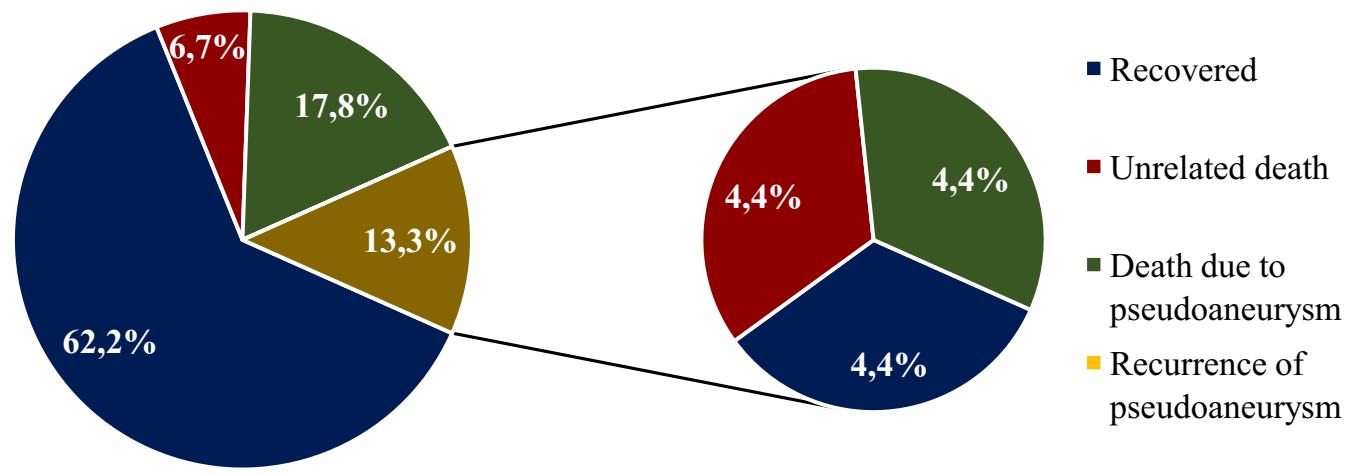

Fig. 5 Outcomes of heart transplant patients diagnosed with ascending aortic mycotic pseudoaneurysms. Based on literature review, almost two-thirds of heart transplant patients recovered after treatment of their ascending aortic mycotic pseudoaneurysms. A sixth of patients died due to the pseudoaneurysm itself, an eighth of them suffered recurrence, while one fifteenth of patients died due to an unrelated cause. Among patients with recurrent pseudoaneurysms, ratio of recovery, pseudoaneurysm-related death and unrelated death was equal (49 cases reviewed, missing data in 4 cases)

Pseudomonas mycotic pseudoaneurysm in a heart transplant recipient has never been described before.

Possible symptoms of mycotic aortic pseudoaneurysms are malaise $[4,18,22,28]$, chest $[6,8,10,12,28,32]$ or back pain $[6,19,23,33]$, dyspnea $[17,25,27,30]$, hoarseness $[21,30]$ or fever $[4,6,8,9,12,13,17-19,22,23,27$, 31-33]. However, completely asymptomatic cases are also reported [25, 26, 34, 37].

The patient demonstrated in the current case was almost fully asymptomatic except of an unexplainable weight loss. Weight loss as an usual general symptom of aortic pseudoaneurysm is reported in the literature as well and may be caused by the inflammatory state [11].

In the case of aortic pseudoaneurysm, common laboratory findings-also seen in our patient-are elevated serum CRP level and elevated white cell count, predominantly neutrophils $[6,23,28,37]$. Highly elevated erythrocyte sedimentation rate is also documented as an alarming sign [37].

Early diagnosis, surgical intervention and adjuvant antibiotic therapy seem to be the keys to successful management of mycotic pseudoaneurysms after HTX. Based on literature data of heart transplant patients with ascending aortic mycotic pseudoaneurysms with a median followup time of 8 months after diagnosis, almost two-thirds of patients recovered after operation $[4-7,9,10,13-15,17$, $21,23,24,26-32,34,35,37$ ], a sixth of them died due to pseudoaneurysm $[4,6,8,14,16,25,33]$, and an eighth of them presented with a recurrent pseudoaneurysm later [7, 8, 12, 19-21]. Median time between first surgical treatment for pseudoaneurysm and the verification of recurrence was 2 months. At the remaining cases (one fifteenth of patients), death due to an unrelated cause occured $[8,14,18]$. One-third of patients treated due to recurrent pseudoaneurysm recovered [12, 20], one-third of them died due to pseudoaneurysm [8,21], and one third died due to other reason $[7,19]$ (Fig. 5).

It is obvious that the choice of antibiotic should be based on the culture and sensitivity of the isolated organism. Nevertheless, duration of intravenous and oral antibiotics in the case of $P$. aeruginosa aortitis after heart transplantation varies $[7,14,18,19,21-23]$ and permanent antibiotic therapy is recommended by some relevant literature datas $[19,23]$. Our strategy was the administration of targeted parenteral antibiotic treatment followed by continuous oral ciprofloxacin therapy. Systemic immunosuppression and synthetic aortic graft material are potential risk factors for recurrent graft infection, therefore, it is worth considering lifelong antibiotic treatment. However, it is also important to take care of potential side effects of permanent ciprofloxacin therapy including an increased risk of aortic aneurysm or dissection [38, 39].

In conclusion, we presented a patient in whom a $P$. aeruginosa pseudoaneurysm of the ascending aorta developed after HTX. In this case no obvious concomitant infection was found at the patient and donorderived infection is suspected. This case demonstrates the importance of considering a mycotic pseudoaneurysm of the aorta in the etiology of unexplainable inflammation following HTX, even if the patient is almost asymptomatic. Surgical intervention and targeted antibiotic treatment are equally essential. $P$. aeruginosa as a causative organism may require long-term antibiotic therapy. 


\section{Abbreviations}

CPB: Cardiopulmonary bypass; CRP: C-reactive protein; CT: Computed tomography; EMB: Endomyocardial biopsy; HTX: Heart transplantation; min: Minute; N/A: Not available; P. aeruginosa: Pseudomonas aeruginosa; TTE: Transthoracic echocardiography.

\section{Acknowledgements}

Not applicable.

\section{Authors' contributions}

SzK took part in the postoperative clinical care and follow up of the patient, collected and summarized patient data, reviewed the relevant literature and was a major contributor in writing the manuscript. MP was responsible for determining the need for and the type of operation. He was also the operating surgeon and wrote the chapter about surgical treatment of the patient. ÁKi organized the diagnosting testing and took part in the postoperative clinical care and follow up of the patient. ÁP performed the CT examination and the three-dimensional CT reconstruction. ÁKo took part in the operation as an assistant surgeon and he also participated in writing the chapter about surgical treatment. TV performed general anesthesia and provided intraoperative transesophageal echocardiographic images. ZsSzT participated in the long term care of the patient and was responsible for interrogation of the outcomes of other transplanted organs from Eurotransplant. NP participated in the long term care of the patient and performed the intraoperative photographs. TT and ZT took part in the postoperative care and follow up of the patient as well. GyP was our infectious disease consultant who guided the antibiotic therapy of the patient. IH and ZSz took part in planning of the surgery. BM took part in planning of the operation and supervised the pre- and postoperative care of the patient. BS took a major part in the postoperative care and follow up of the patient and was also in charge of supervising the manuscript. All authors read and approved the final manuscript.

\section{Funding}

No funding body had any role in the completion of this case report.

\section{Availability of data and materials}

All data supporting the conclusions of this article are included within the article.

\section{Declarations}

\section{Ethics approval and consent to participate}

An ethics approval was not necessary because all data was acquired through diagnostic tests and therapeutic interventions performed for clinical purposes. The patient signed an institutional informed consent for receiving treatments.

\section{Consent for publication}

A written informed consent was obtained from the patient for the publication of this case report, and any accompanying images.

\section{Competing interests}

The authors declare that they have no competing interests.

\section{Author details}

${ }^{1}$ Heart and Vascular Center, Semmelweis University, 68 Városmajor Street, 1122 Budapest, Hungary. ${ }^{2}$ Department of Anesthesiology and Intensive Therapy, Semmelweis University, 68 Városmajor Street, 1122 Budapest, Hungary.

\section{Received: 10 June 2021 Accepted: 10 August 2021}

Published online: 21 August 2021

\section{References}

1. Sullivan KL, Steiner RM, Smullens SN, Griska L, Meister SG. Pseudoaneurysm of the ascending aorta following cardiac surgery. Chest. 1988;93:138-43.

2. Sommerville RL, Allen EV, Edwards JE. Bland and infected arteriosclerotic abdominal aortic aneurysms: a clinicopathologic study. Medicine. 1959;38:207-21.
3. Osler W. The gulstonian lectures, on malignant endocarditis. Br Med J. 1885;1:467-70.

4. Thomson D, Menkis A, Pflugfelder P, Kostuk W, Ahmad D, McKenzie FN. Mycotic aortic aneurysm after heart-lung transplantation. Transplantation. 1989;47:195-7.

5. Slater AD, Ganzel BL, Keller M, Tobin GR 2nd, Gray LA Jr. Repair of infected pseudoaneurysm with aortic arch replacement after orthotopic heart transplantation. J Heart Transplant. 1990;9:230-5.

6. Anthuber M, Kemkes BM, Kreuzer E, Gokel M, Schuetz A, Kugler C, Sudhoff F. Mediastinitis and mycotic aneurysm of the aorta after orthotopic heart transplantation. Tex Heart Inst J. 1991;18:186-93.

7. Knosalla C, Weng Y, Yankah AC, Hofmeister J, Hetzer R. Using aortic allograft material to treat mycotic aneurysms of the thoracic aorta. Ann Thorac Surg. 1996;61:1146-52.

8. Vigano M, Rinaldi M, D'Armini AM, Pederzolli C, Minzioni G, Grande AM. The spectrum of aortic complications after heart transplantation. Ann Thorac Surg. 1999;68:105-11.

9. Omoto T, Minami K, Muramatsu T, Kyo S, Körfer R. Ann Thorac Surg. 2001;72:263-4.

10. Omoto T, Minami K, Deyerling KW, Tenderich G, Breymann T, Körfer R. Aortoplasty with a bovine venous xenograft for pseudoaneurysm after heart transplantation. J Cardiovasc Surg. 2004;45:149-51.

11. Dumont E, Carrier M, Cartier R, Pellerin M, Poirier N, Bouchard D, Perrault LP. Repair of aortic false aneurysm using deep hypothermia and circulatory arrest. Ann Thorac Surg. 2004;78:117-21.

12. Milner R. Treating a Mycotic Ascending Aortic Aneurysm. Isolated endovascular therapy can be performed successfully in appropriate anatomy. In: Endovascular today. 2007. https://evtoday.com/pdfs/ EVT0407_11.pdf. Accessed Apr 2007.

13. Patané F, Sansone F, Campanella A, Attisani M, Rinaldi M. Mycotic pseudoaneurysm as aortic complication after heart transplantation. Transpl Int. 2009;1:943-4.

14. Tang GHL, Pinney SP, Broumand SR, Adams DH, Anyanwu AC. Excellent outcomes with use of synthetic vascular grafts for treatment of mycotic aortic pseudoaneurysms after heart transplantation. Ann Thorac Surg. 2011;92:2112-7.

15. Joyce DL, Singh SK, Mallidi HR, Dake MD. Endovascular management of pseudoaneurysm formation in the ascending aorta following lung transplantation. J Endovasc Ther. 2012;19:52-7.

16. Goekler J, Zuckermann A, Osorio E, Brkic FF, Uyanik-Uenal K, Laufer G, Aliabadi-Zuckermann A. Cardiac surgery after heart transplantation: elective operation or last exit Strategy? Transplant Direct. 2017;3:e209.

17. Skrabonja-Crespo A, Chavarri-Velarde F, Pinto-Salinas M, Tauma-Arrué A. Percutaneous endovascular management of ascending aortic pseudoaneurysm after heart transplantation in a pediatric patient. Pediatr Transplant. 2021;25:e13958.

18. Palac RT, Strausbaugh LJ, Antonovic R, Floten HS. An unusual complication of cardiac transplantation-infected aortic pseudoaneurysm. Ann Thorac Surg. 1991;51:479-81.

19. Cassart M, Gevenois PA, Knoop C, Antoine M, Vachiéry JL, Leclerc JL, Struelens M, Nonhoff C, Jacobs F, Serruys E. Pseudomonas aeruginosa aortic aneurysm after heart-lung transplantation for cystic fibrosis. Transplantation. 1994;58:1051-3.

20. McGiffin DC, Galbraith AJ, McCarthy JB, Tesar PJ. Mycotic false aneurysm of the aortic suture line after heart transplantation. J Heart Lung Transplant. 1994;13:926-8.

21. Koyanagi T, Minami K, Tenderich G, Reiss N, Morshius M, Mirow N, Körfer R. Thoracic and cardiovascular interventions after orthotopic heart transplantation. Ann Thorac Surg. 1999;67:1350-4.

22. Mirzaee S, Habibian M, Wong Y. A case of mycotic aneurysm of the ascending aorta at the suture line early post orthotopic heart transplantation. Heart Lung Circ. 2016;25(Suppl):94.

23. Aye $C$, Williams $M$, Horvath R. Multidrug resistant pseudomonas mycotic pseudoaneurysm following cardiac transplant bridged by ventricular assistant device. Case Rep Infect Dis. 2017. https://doi.org/ 10.1155/2017/1402320.

24. Oaks TE, Pae WE, Pennock JL, Myers JL, Pierce WS. Aortic rupture caused by fungal aortitis: successful management after heart transplantation. J Heart Transplant. 1988;7:162-4. 
25. Dowling RD, Baladi N, Zenati M, Dummer JS, Kormos RL, Armitage JM, Yousem SA, Hardesty RL, Griffith BP. Disruption of the aortic anastomosis after heart-lung transplantation. Ann Thoruc Surg. 1990;49:118-22.

26. Berggren H, Berglin E, Kjellman U, Mantovani V, Nilsson B. Successful outcome after massive bleeding in a heart transplant recipient with mycotic aortitis. Scand J Thor Cardiovasc Surg. 1994;28:45-7.

27. Kamineni R, Lui CY, Copeland JG. Severe obstruction of the left main coronary artery by mycotic aortic psuedoaneurysm following orthotopic heart transplantation. J Heart Lung Transplant. 2004;23:499-502.

28. Fraser CD 3rd, Arnaoutakis GJ, George TJ, Owens JB, Conte JV, Shah AS Acute cholecystitis preceding mycotic aortic pseudoaneurysm in a heart transplant recipient. J Card Surg. 2010;25:749-51.

29. Castro RBA, Kai M, Ohira S, Spielvogel D, Gass A. Surgical repair of candida mycotic pseudoaneurysm with extensive vegetations of the ascending aorta and pulmonary artery after heart and kidney transplant. J Card Surg. 2020;35:3585-7.

30. Palanichamy N, Gregoric ID, La Francesca S, Smart FW. Mycotic pseudoaneurysm of the ascending thoracic aorta after cardiac transplantation. J Heart Lung Transplant. 2006;25:730-3.

31. Yamane K, Hirose H, Mather PJ, Silvestry SC. Mycotic pseudoaneurysm of the ascending aorta after heart transplantation: case report. Transplant Proc. 2011:43:2055-8.

32. Guyot S, Goy JJ, Gersbach P, Jaton K, Blanc DS, Zanetti G. Legionella pneumophila aortitis in a heart transplant recipient. Transpl Infect Dis. 2007;9:58-9.

33. Byl B, Jacobs F, Antoine M, Depicrreux M, Scrruys E, Primo G, Thys JP. Mediastinitis caused by Aspergillus fumigatus with ruptured aortic pseudoaneurysm in a heart transplant recipient: Case study. Heart Lung. 1993;22:145-7.

34. Ronco F, Simsir S, Czer L, Luo H, Siegel RJ. Incidental finding by twodimensional echocardiography of a mycotic pseudoaneurysm of the ascending aorta after orthotopic heart transplantation. J Am Soc Echocardiogr. 2010;23(580):e1-3.

35. Vogt PR, Hasler E, Schmidlin D, Berdat PT, Went P, Flepp M, Mohasci P. Mycotic Aneurysm of the Ascending Aorta and Aspergillus fumigatus Mediastinitis Early after Cardiac Transplantation. Clin Surg. 2017;2:1681.

36. Taylor DO, Rehr RB, Thompson JA, Vetrovec G, Tatum JL. Aortic pseudoaneurysm occurring after cardiac transplantation. Am Heart J. 1990;120:1222-5.

37. Behzadnia N, Ahmadi ZH, Mandegar MH, Salehi F, Sharif Kashani B, Pourabdollah M, Ansari-Aval Z, Kianfar AA, Mirhosseini SM, Eiji M. Asymptomatic mycotic aneurysm of ascending aorta after heart transplantation: a case report. Transplant Proc. 2015:47:213-6.

38. Pasternak B, Inghammar M, Svanström H. Fluoroquinolone use and risk of aortic aneurysm and dissection: nationwide cohort study. BMJ. 2018;360:k678.

39. Carino D, Zafar MA, Singh M, Ziganshin BA, Elefteriades JA. Fluoroquinolones and aortic diseases: is there a connection. Aorta. 2019;7:35-41.

\section{Publisher's Note}

Springer Nature remains neutral with regard to jurisdictional claims in published maps and institutional affiliations.
Ready to submit your research? Choose BMC and benefit from:

- fast, convenient online submission

- thorough peer review by experienced researchers in your field

- rapid publication on acceptance

- support for research data, including large and complex data types

- gold Open Access which fosters wider collaboration and increased citations

- maximum visibility for your research: over $100 \mathrm{M}$ website views per year

At BMC, research is always in progress.

Learn more biomedcentral.com/submissions 